\title{
Isolation and Identification of Bacteria from Swollen Head Syndrome (SHS) Affected Chicken Flock
}

\author{
M. Ruthra*, A. Arulmozhi, A.Balasubramaniam and G. A. Balasubramaniam \\ Department of Veterinary Pathology, Veterinary College and Research Institute, \\ TANUVAS, Namakkal- 637002, Tamil Nadu, India \\ *Corresponding author
}

\section{A B S T R A C T}

\section{Keywords}

Swollen Head Syndrome (SHS), bacterial culture, PCR, Chicken

Article Info

Accepted:

10 July 2020

Available Online:

10 August 2020
The purpose of this study was designed to isolate and identify the bacterial organisms from the chicken flocks which are affected by Swollen Head Syndrome (SHS) in and around Namakkal, Tamil Nadu. Clinical materials like infraorbital sinus swabs, chonal cleft swabs, tracheal swabs and lungs were collected for the bacterial culture. Suspected bacterial cultures were used for biochemical tests and PCR. Out of 48 positive flocks, 9 got positive for Avibacterium paragallinarum, 8 for Mycoplasma gallisepticum and remaining flocks are positive for Escherichia coli in combination with Avian metapneumovirus, Staphlylococcus spp., Pseudomonas spp., and Pasteurella spp., This suggests that SHS can be associated with most of the bacteria other than pneumovirus.

\section{Introduction}

Swollen Head Syndrome (SHS) is an acute highly contagious upper respiratory tract infection primarily of chicken and turkeys caused by avian metapneumovirus (aMPV) (OIE manual, 2009). The damage to upper respiratory organs like sinus, turbinates and trachea may lead to clinical signs such as nasal discharge, coughing, sneezing and more complicated respiratory problems. This stress on the cilia and upper respiratory tract can facilitate the multiplication of E. coli and other bacterial infections such as Staphylococcus spp., Mycoplasma gallisepticum, Pasteurella spp., Bordetella spp. and Ornithobacterium rhinotracheale etc. that lead to a respiratory syndrome called swollen head syndrome (Jones et al., 1988). The present study was conducted to rule out the concurrent bacterial infections in the SHS affected birds.

\section{Materials and Methods}

\section{Clinical materials}

From 48 positive flocks, choanal cleft swabs, infraorbital sinus swabs, trachea and lung samples were collected from the birds with 
the respiratory signs like coughing, respiratory rales and swollen infraorbital sinus.

\section{Culture media}

The media like nutrient agar, mannitol salt agar, Brain Heart Infusion (BHI) agar, chocolate agar, MacConkey agar, Eosin Methylene Blue agar (EMB) and Triple Sugar Iron (TSI) broth were used to isolate and identify the bacteria associated with SHS.

\section{PCR}

\section{Avibacterium paragallinarum primers}

Sequence of primers used for amplification of $16 \mathrm{~S}$ rRNA gene that produced a $500 \mathrm{bp}$ fragment (Nouri et al., 2014) was as follows:

Forward primer: $\quad$ 5'-TGA GGG TAG TCT TGC ACG CGA AT-3'

Reverse primer: 5'-CAA GGT ATC GAT CGT CTC TCT ACT-3'

\section{Mycoplasma gallisepticum primers}

Sequence of primers used for amplification of $16 \mathrm{~S}$ rRNA that produced a $530 \mathrm{bp}$ fragment (Kiss et al., 1997) was as follows:

Forward primer: 5 '- AAC ACC AGA GGC GAA GGC GAG G-3'

Reverse primer: $\quad$ 5'-ACG GAT TTG CAA CTG TTT GTA TTG G-3'

\section{Results and Discussion}

Clinical signs suggestive of swollen head syndrome (SHS) were investigated in 54 flocks of broiler and layer chicken situated in and around Namakkal district. Out of these, 48 flocks were positive for viral and concurrent bacterial infections. E. coli alone was isolated from 19 affected flocks. E.coli with Staphylococcus spp. was isolated from 6 flocks and Pseudomonas spp. with E.coli and Staphylococcus spp. in 3 flocks, E.coli with Avibacterium paragallinarum (AP) in 9 flocks, E.coli with Mycoplasma gallisepticum (MG) in 8 flocks and Pasteurella spp. was isolated from 2 flocks.

\section{Detection of secondary bacterial agents by culture}

Infraorbital sinus and heart blood swabs were collected from all the 54 flocks and were subjected to bacteriological isolation using selective culture media.

\section{Escherichia coli}

Escherichia coli organisms were identified based on round, smooth, glistening and lactose fermenting pink colour colonies in MacConkey's agar and green metallic sheen colonies in Eosin Methylene Blue (EMB) agar (Fig. 1). The confirmatory test was done with triple sugar iron (TSI) slant. The slant and butt was turned into yellow colour without $\mathrm{H}_{2} \mathrm{~S}$ production (Fig. 2). In the present study, E. coli was the major organism responsible for SHS in most of the flocks. $E$. coli affected the chicken as individual or combined infection with aMPV and other bacteria. These findings are in accordance with Barnes et al., (2003) and Paul (1998) who recovered $E$. coli from the purulent lesions in skull bone of SHS affected chicken.

\section{Avibacterium paragallinarum}

In chocolate agar, transparent minute colonies of Avibacterium paragallinarum were observed and their size ranged from pinpoint to $1 \mathrm{~mm}$ diameter within $24 \mathrm{~h}$ and $0.5-1.5$ $\mathrm{mm}$ in $48 \mathrm{~h}$ (Fig. 3). Smears prepared from these colonies revealed pleomorphic Gram- 
negative coccobacilli (Fig. 4). The isolates were found to be negative for catalase, urease, indole production and positive for oxidase. These findings are in agreement with the early report by Quinn et al., (1994). The fastidious nature of Avibacterium paragallinarum and subsequent requirement for special media has made the isolation and identification of this organism difficult (Chen et al., 1998).

\section{Pasteurella spp.}

Fine, dew drop like colonies of Pasteurella spp. were noticed in Brain Heart Infusion (BHI) agar (Fig. 5). Smear prepared from single colony revealed Gram-negative rods which were non-motile and non-spore forming. Arrangement was either single or paired and occasionally as chains or filamentous appearance. Bipolar organisms were observed in lung impression smears by Giemsa staining (Fig. 6) denoted the emergence of Pasteurella spp. as and when birds at stake due to any kind of stress, infection with other pathogens as observed in this study. Similar findings were reported by Rhoades and Rimler (1991).

\section{Staphylococcus spp.}

Round, milky white colonies of Staphylococcus spp. were produced in nutrient and BHI agar. Whereas, minute, yellow colour colonies were observed (Fig. 7) in Mannitol Salt Agar (MSA). Smears prepared from these colonies revealed clusters or bunches of Gram-positive cocci.

These results are comparable with the findings of Quinn et al., (2002). Paul (1998) and Nakamura et al., (1997) recovered Staphylococcus spp. and Proteus spp. from the nasal cavities of chicken affected with SHS.

\section{Pseudomonas spp.,}

Green colour discolouration of MacConkey's and nutrient agar (Fig. 8) was noticed due to production and release of pyocyanin by Pseudomonas spp. These observations are in accordance with Quinn et al., (2002). Presence of Pseudomonas spp. organisms indicates that there was severe immunosuppression among ailing birds from which samples were drawn.

Fig.1 E.coli: Green metallic sheen appearance of colonies in Eosin Methylene Blue (EMB) agar

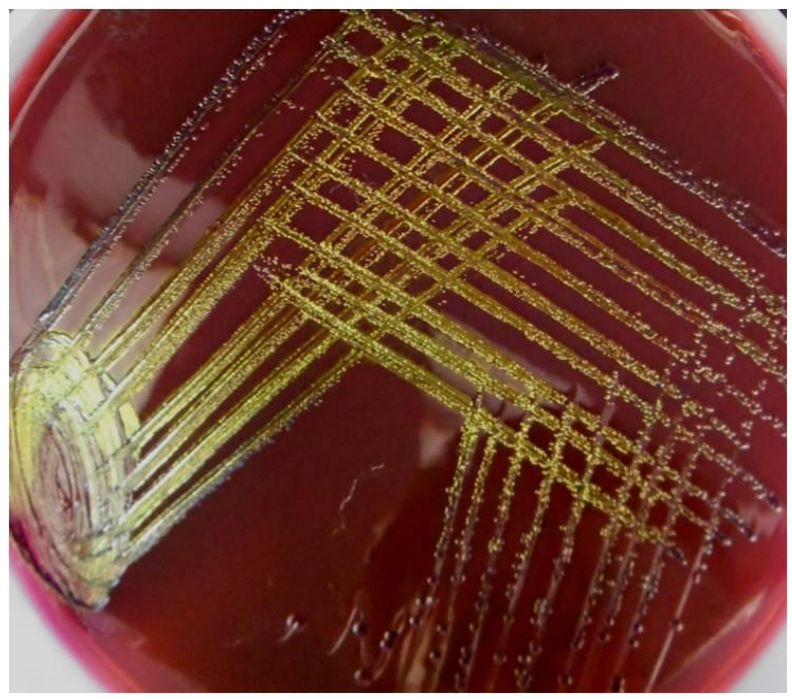


Fig.2 E.coli: Yellow slant, yellow butt and no $\mathrm{H}_{2} \mathrm{~S}$ production in Tripe Sugar Iron (TSI) slant

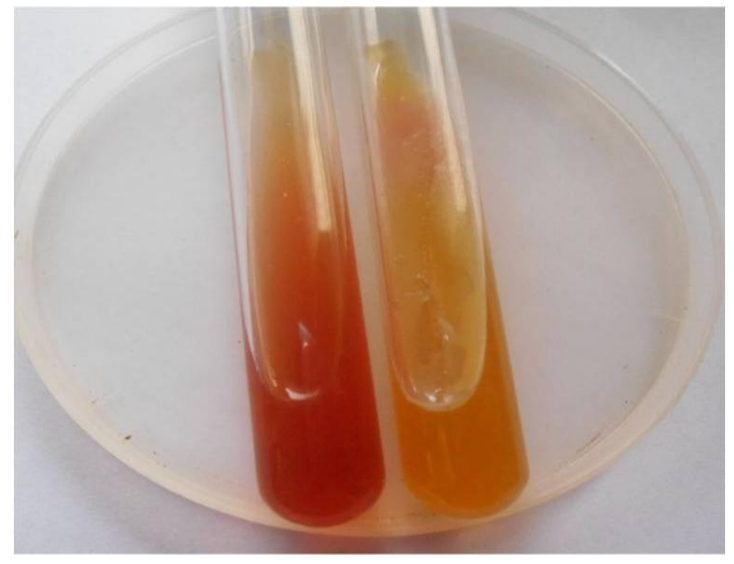

Fig.3 A. paragallinarum: Transparent minute colonies in chocolate agar

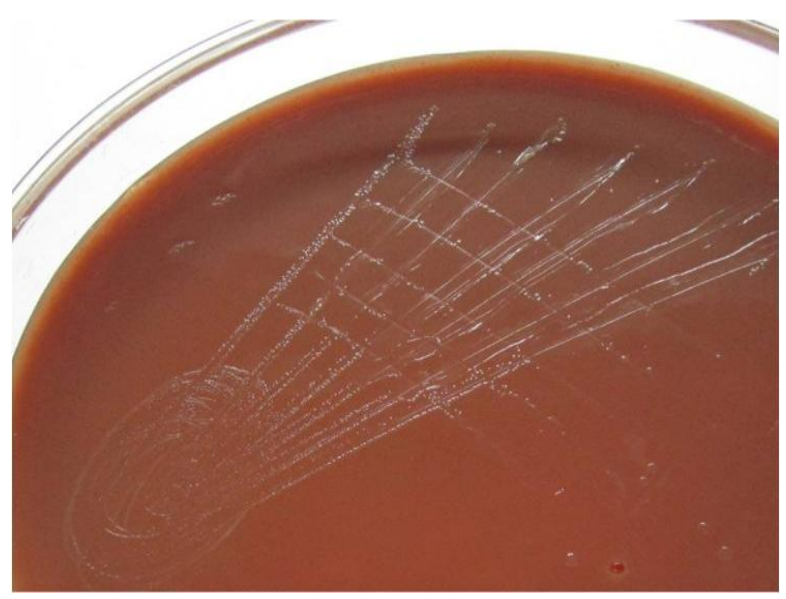

Fig.4 A. paragallinarum: Gram-negative pleomorphic coccobacilli in Gram staining Gram's x 1000

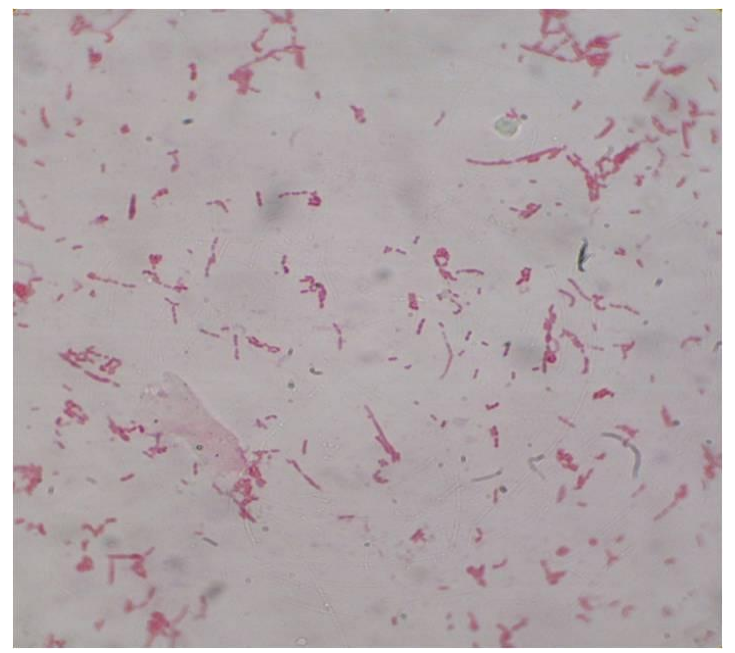


Fig.5 Pasteurella spp: Fine dew drops like colonies in Brain Heart Infusion (BHI) agar

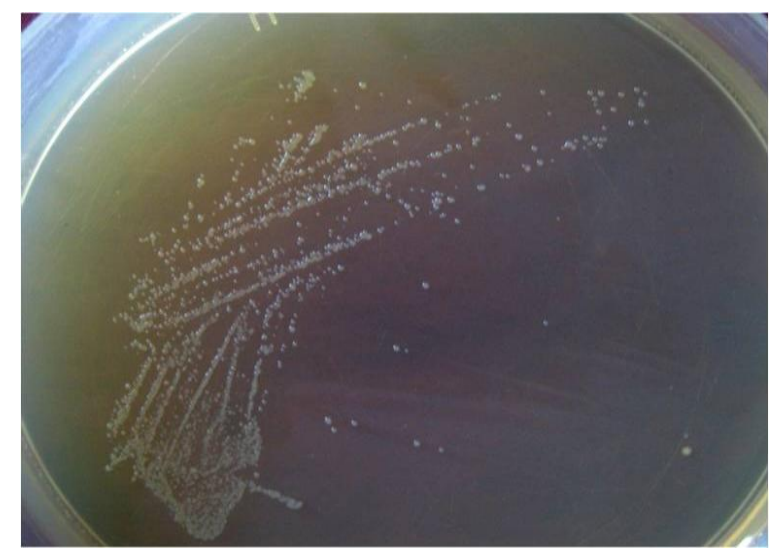

Fig.6 Pasteurella spp: Bipolar organisms (arrows) in lung impression smear by Giemsa staining Giemsa x 1000

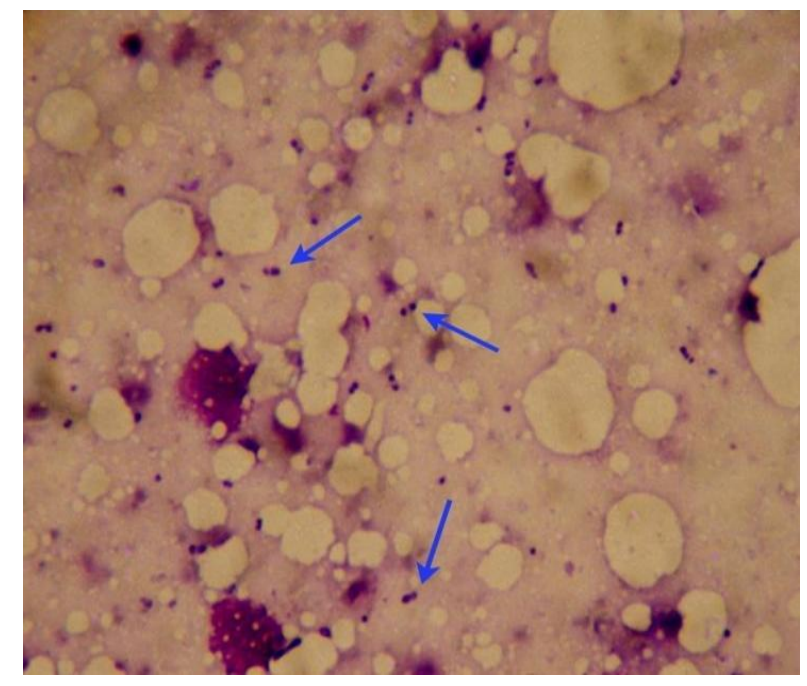

Fig.7 Staphylococcus spp: Minute yellow coloured colonies in mannitol salt agar

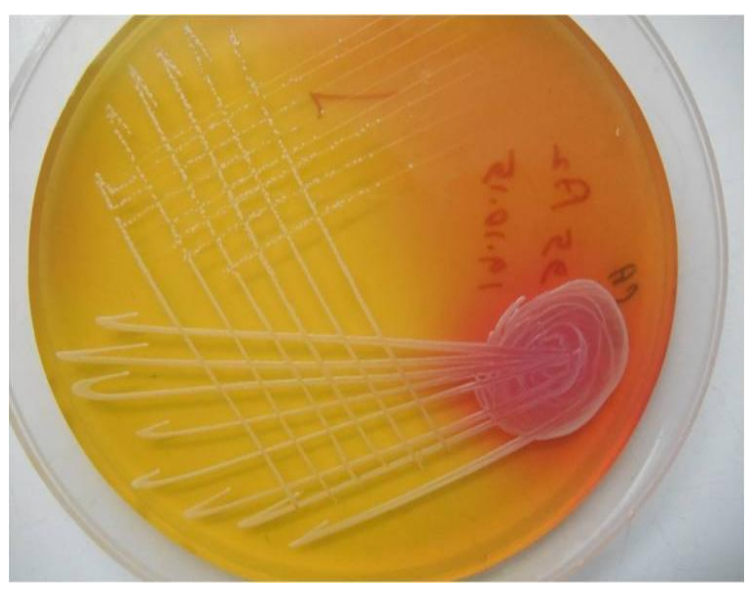


Fig.8 Pseudomonas spp.: Green colour discolouration of nutrient agar due to pyocyanin production

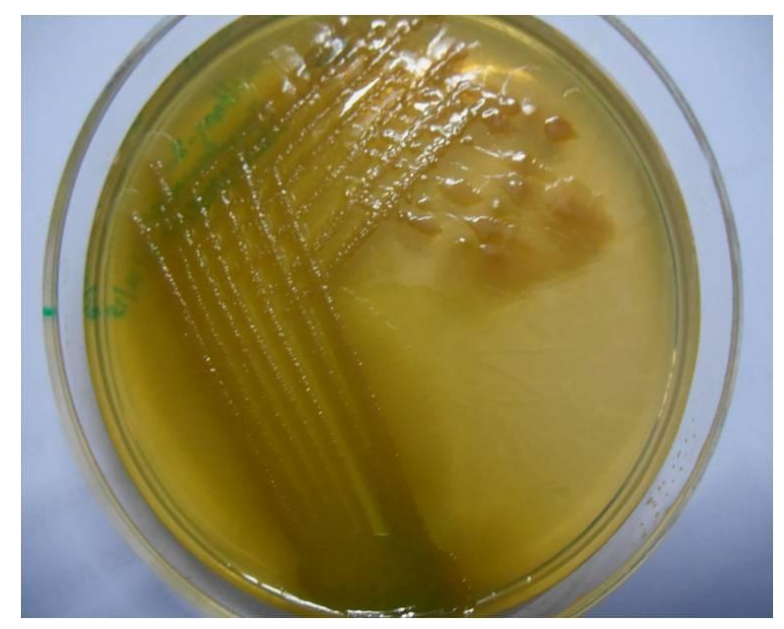

Fig.9 Avibacterium paragallinarum: 500 bp PCR product of 16S rRNA gene on $1.5 \%$ agarose gel

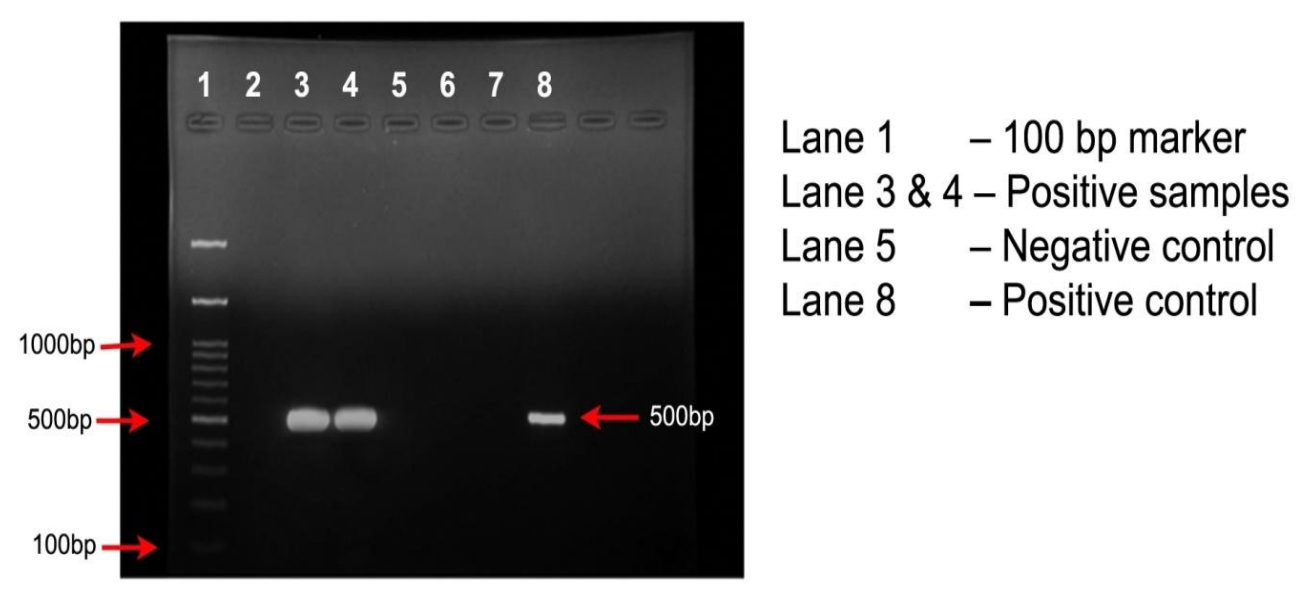

Fig.10 Mycoplasma gallisepticum: 530 bp PCR product of 16S rRNA gene on 1.5\% agarose gel

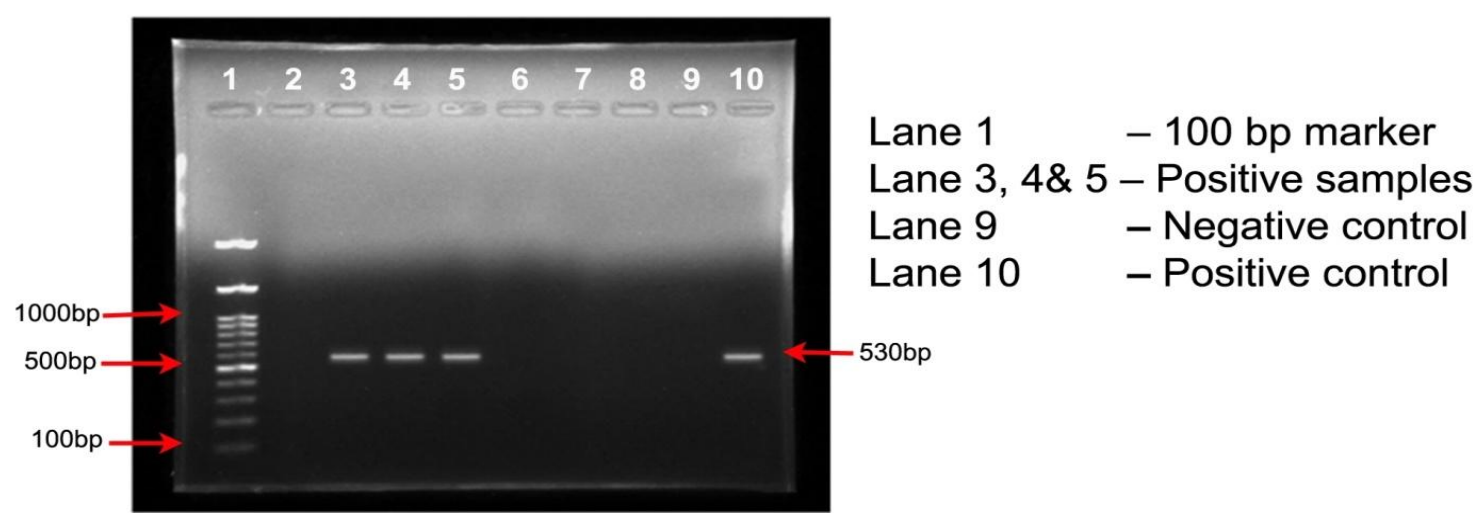




\section{Detection of secondary bacterial agents by PCR}

\section{Avibacterium paragallinarum}

Isolation and identification of Avibacterium paragallinarum by PCR reduces the complexity of the diagnostic task (Chen et al., 1998). Avibacterium paragallinarum nucleic acid was detected in 9 out of 48 flocks. DNA was extracted by Genomic DNA purification kit from the isolated colonies and screened for $16 \mathrm{~S}$ rRNA gene which produced band at 500 bp in gel electrophoresis (Fig. 9). These results are supported by Badouei et al., (2014) who used a primer pair complementary to specific gene designated for the detection of AP. In this study, all culture positive samples were also positive by PCR for Avibacterium paragallinarum. This denotes that PCR could be relied upon for detection of AP, thus saving time and labour.

\section{Mycoplasma gallisepticum}

DNA was extracted by Genomic DNA purification kit from triturated tissue samples of trachea, lung and liver. The samples were subjected to PCR to screen 16S rRNA gene of MG at 530 bp (Fig. 10) and showed positivity for 8 flocks. The obtained results are concurred with earlier reports by Kiss et al., (1997) and Ramadass et al., (2006).

\section{References}

Barnes, H.J., Vaillancourt, J.P. and Gross, W.B. 2003. Colibacillosis, In: Saif Y.M. et al., (eds.): Diseases of Poultry, 11th Edn. Iowa State University Press, Ames, Iowa, USA. pp. 631 - 652.

Chen, X., Chen, Q., Zhang, P., Feng, W and Blackall, P.J. 1998. Evaluation of PCR test for the detection of Haemophilus paragallinarum in china. Avian Pathol., 27: 296-300.
Jones, R.C., Williams R.A., Baxter-Jones, C., Savage, C.E and Wilding, G.P. 1988. Experimental infection of laying turkeys with rhinotracheitis virus: distribution of virus in the tissues and serological response. Avian Pathol., 17: $841-850$.

Kiss, I., Matiz, K., Kaszaryitzky, E., Chavez, Y and Johansson, K.F. 1997. Detection and identification of avian mycoplasmas by polymerase chain reaction and restriction fragment length polymorphism assay. Vet. Microbiol., 58: 23 - 30 .

Nakamura, K., Mase, M., Tanimura, N., Yamaguchi, S., Nakazawa, $\mathrm{M}$ and Yuasa, N. 1997. Swollen head syndrome in broiler chickens in Japan: its pathology, microbiology and biochemistry. Avian Pathol., 26: 139 154.

Nouri, A., Banani, M., Goudrzi, H., Pourbakhsh, S.A and Mirzaei, S.G. 2014. Retrospective detection of Avibacterium paragallinarum serovar $B$ in egg yolk materials by PCR. Archives of Razi Institute. 69: 179 183.

OIE Terrestrial Manual. 2009. Turkey rhinotracheitis (avian metapneumovirus infections). Chapter 2.3.15, pp 1 13.

Paul McMullin. 1998. Diagnosis, management and control of avian pneumovirus infection in broiler parent chickens. Poultry Health Services. Poultry Health Centre, Main Site Lane, Dalton, Thirsk, North Yorkshire, YO7 3JA U.K.

Quinn, P.J., Carter, M.E., Markey, B and Carter, G.R. 1994. Haemophilus paragallinarum. In Clinical Veterinary Microbiology. Mosby Year Book Europe Limited. Wolfe. Pp. 277.

Quinn, P.J., Markey, B.K., Carter, M.E., Donnelly, W.J and Leonard, F.C. 2002. 
Veterinary Microbiology and Microbial disease. Blackwell science Ltd.

Ramadass, P., Ananth, R., Senthilkumar, T.M.A., Venkatesh, $\mathrm{G}$ and Ramaswamy, V. 2006. Isolation and characterization of Mycoplasma gallisepticum and Mycoplasma synoviae from poultry. Indian J. Anim.
Sci., 76 (10): 796 - 798. Rhoades, K.R and Rimler, R.B. 1991. Pasteurellosis, In: B.W. Calnek, H.J. Barnes, C.W. Beard, W.M. Reid and H.W. Yoder Jr (Eds), In Diseases of Poultry, 9th edn. Iowa state university press, Ames, Iowa. 145 - 171.

\section{How to cite this article:}

Ruthra, M., A. Arulmozhi, A.Balasubramaniam and Balasubramaniam, G. A. 2020. Isolation and Identification of Bacteria from Swollen Head Syndrome (SHS) Affected Chicken Flock. Int.J.Curr.Microbiol.App.Sci. 9(08): 359-366. doi: https://doi.org/10.20546/ijcmas.2020.908.042 